Jurnal Riset Agama

Volume 1, Nomor 2 (Agustus 2021): 428-438

DOI: $10.15575 /$ jra.v1i2.14709

https://journal.uinsgd.ac.id/index.php/jra

\title{
Pencegahan Perilaku Boros sebagai Self Healing dalam Penggunaan Online Shopping: Studi Takhrij dan Syarah Hadis
}

\author{
Yabqiah Rahmi \\ Jurusan Ilmu Al-Qur'an dan Tafsir,Fakultas Ushuluddin \\ UIN Sunan Gunung Djati Bandung, Indonesia \\ yabqiahrahmi@gmail.com
}

\begin{abstract}
This study aims to analyze the hadith about the prevention of wasteful behavior as self-healing. This study uses a qualitative approach that emphasizes literature study through the takhrij and syarah hadith methods with contemporary analysis. The results of the research and discussion show that the hadith regarding the prevention of wasteful behavior as self-healing has authentic quality so that it can be practiced and used as an argument. The explanation of this hadith shows that giving, tithing and shadaqah are behaviors to prevent waste and for self-healing by means of shopping are allowed but must be in accordance with the budget and limitations. The conclusion of this study is that self-healing through shopping is not something that is prohibited but must be accompanied by giving infaq, giving charity, and tithing because in our assets there are other people's rights; namely the poor, relatives in need, and Ibn Sabil who ran out of provisions.
\end{abstract}

Keywords: Extravagant behavior; Hadith; Prevention; Self-healing.

\begin{abstract}
Abstrak
Penelitian ini bertujuan untuk menganalisis hadis tentang pencegahan perilaku boros sebagai self healing. Penelitian ini menggunakan pendekatan kualitatif yang ditekankan pada studi pustaka melalui metode takhrij dan syarah hadis dengan analisis kontemporer. Hasil penelitian dan pembahasan menunjukkan bahwa hadis tentang pencegahan perilaku boros sebagai self healing berkualitas shahih sehingga dapat diamalkan serta dijadikan dalil. Adapun penjelasan hadis ini menunjukkan bahwa berinfak, berzakat dan bershadaqah merupakan perilaku untuk mencegah pemborosan dan untuk self healing dengan cara berbelanja diperbolehkan tetapi harus sesuai dengan anggaran dan batasan. Kesimpulan penelitian ini adalah bahwa self healing melalui cara berbelanja bukanlah hal
\end{abstract}


Jurnal Riset Agama, Volume 1, Nomor 2 (Agustus 2021): 428-438

Yabqiah Rahmi/Pencegahan Perilaku Boros sebagai Self Healing dalam

Penggunaan Online Shopping: Studi Takhrij dan Syarah Hadis

yang dilarang tetapi harus dibarengi dengan berinfaq, bershadaqah, dan berzakat karena dalam harta kita terdapat hak orang lain; yaitu orang miskin, kerabat yang membutuhkan, dan ibnu sabil yang kehabisan bekal.

Kata kunci: Hadis; Pencegahan; Perilaku boros; Self healing.

\section{Pendahuluan}

Masyarakat modern menjadi bagian penting sebagai objek perkembangannya, serta menjadi sasaran pasar terhadap apa yang mereka dagangkan dan produksi (Najieb, 2012b). Pemborosan dalam berbelanja menjadi salah satu dampak dari dunia modern. Survey membuktikan bahwa perempuanlah yang paling banyak melakukan pembelian secara berlebih-lebihan, Alasannya karena perempuan lebih cenderung membutuhkan penyaluran jika mengalami permasalahan pribadi (Retno Mangestuti, 2014). Faktor psikologis menjadi salah satu hal yang menyebabkan pembelian secara berlebih-lebihan (Retno Mangestuti, 2014). Contoh faktor dari psikologis itu ialah Self healing. Self healing merupakan salah satu cara untuk memberikan apresiasi atau menyenangkan diri sendiri. Dengan adanya self healing, otak akan mengaitkan kata healing dengan kerja keras dan pola pikir tersebut akan menjadi acuan atau motivasi kepada diri untuk mengerjakan pekerjaan lain dengan semangat. Namun yang menjadi masalah ialah ketika otak telah menyetel atau mengasosiasikan kata healing dengan sesuatu hal yang tidak baik seperti pemborosan. Pemborosan dalam berbelanja dilakukan hanya untuk memperoleh kesenangan atau untuk mencapai kepuasan maksimal (García Reyes, Luis Enrique, 2013). Kebahagian yang diciptakan hanya untuk memenuhi nafsu saja akan bersifat semu. Keinginan untuk memuaskan kesenangan seringkali mendorong seseorang untuk membeli barang yang sebenarnya tidak dibutuhkan (Munir, 2015). Umat Islam diajarkan untuk menyisihkan hartanya untuk hal yang bersifat positif seperti mengeluarkan zakat, shadaqah, dan infaq (Hasan Nuddien et al., 2018). Oleh karena itu, ajaran Islam diperlukan untuk mengekang perilaku pemborosan dalam berbelanja menggunakan teori ilmu hadis berikut syarahnya.

Sejumlah ahli telah melakukan penelitian terkait pembahasan pemborosan dan self healing sebagaimana dalam tinjauan pustaka ini. Antara lain Bachtiar and Faletehan (2021), "Self Healing sebagai Metode Pengendalian Emosi," Jurnal An-Nafs Universitas Islam Negeri Sunan Ampel Surabaya. Penelitian pendekatan kuantitatif berbasis desain pre test dan post test menemukan bahwa pelatihan self healing berdampak positif 
Jurnal Riset Agama, Volume 1, Nomor 2 (Agustus 2021): 428-438

Yabqiah Rahmi/Pencegahan Perilaku Boros sebagai Self Healing dalam

Penggunaan Online Shopping: Studi Takhrij dan Syarah Hadis

terhadap kemampuan remaja dalam mengendalikan emosi. Kesimpulan penelitian ini adalah self healing berpengaruh terhadap pengendalian emosi remaja (Bachtiar \& Faletehan, 2021). Choiriyah, M. (2017), "Hadishadis tentang Israf dan Makhillah (Studi Ma'ani al-Hadis)," Institut Agama Islam Negeri Surakarta. Penelitian ini merupakan penelitian kualitatif dengan pendekatan studi makna. Penelitian ini membahas makna ishraf dan makhilah yang terdapat dalam hadis Amad bin Hanbal, Ibn Majah, dan an-Nasa'i. Penelitian ini menyimpulkan bahwa hadis-hadis tentang larangan ishraf dan makhilah dapat memberi dorongan kepada manusia untuk menggunakan barang dengan baik dan bermanfaat serta melarang untuk menggunakan berbuat boros terhadap hal-hal yang tidak penting (Choiriyah, 2017). Japar, Imanuel, Saputra, et al (2020), "Faktor-faktor yang Mempengaruhi Penggunaan Aplikasi Belanja Online pada Masyarakat Indonesia (Studi Empiris pada E-Commerce)," Journal Indonesia Bussines Riview Universitas Prasetya Mulya. Penelitian ini menerapkam penelitian kuantitatif dengan motode; riset berupa survei dengan kuesioner online. Hasil penelitian ini menunjukkan bahwa faktor yang paling berpengaruh terhadap keputusan masyarakat dalam penggunan aplikasi online shop ialah faktor attitude (perilaku). Penelitian ini menyimpulkan bahwa faktor attitude yang paling berpengaruh terhadap keputusan dalam menggunakan aplikasi belanja online (Japar et al., 2020).

Penelitian terdahulu sekaligus tinjauan pustaka bermanfaat terhadap penyusunan kerangka berpikir ini. Penggunaan Internet menjadi salah satu hasil dari kemajuan teknologi. Dengan internet kita dapat melakukan kegiatan berbelanja yang dalam istilah internet sering disebut Online Shop (Fatem, 2015). Online shop adalah kegiatan jual beli yang menggunakan sistem elektronik, yang transaksinya dilakukan dengan sistem pembayaran yang telah ditentukan dan barang akan dikirimkan melaluis jasa pengiriman (Fatem, 2015). Sikap berlebih-lebihan dalam berbelanja dapat dilakukan oleh semua kalangan usia karena dengan berbelanjalah kebutuhan hidup terpenuhi. Menurut Tambunana dalam Garcia Reyes, Luis Enrique (García Reyes, Luis Enrique, 2013), sikap berlebih-lebihan merupakan keinginan untuk mengkonsumsi barang-barnag yang sebenarnya kurang diperlukan secara berlebi-lebihan untuk mencapai kepuasan maksimal. Self healing secara harfiah mengandung makna penyembuhan diri, karena kata healing sendiri diartikan sebagai "a process of cure," suatu proses pengobatan atau penyembuhan (Bachtiar \& Faletehan, 2021). Telah disepakati bahwa hadis adalah sumber ajaran Islan kedua setelah Alqur'an (Misbah, 2021). Para ulama Hadis memberikan definisi hadis sebagai segala sesuatu yang disandarkan kepada Nabi Muhammad Saw yang berupa perbuatan, perkataan, takrir atau sifat (Yuslem, 2001). Takhrij dan syarah merupakan cabang dari ilmu hadis. 
Jurnal Riset Agama, Volume 1, Nomor 2 (Agustus 2021): 428-438

Yabqiah Rahmi/Pencegahan Perilaku Boros sebagai Self Healing dalam

Penggunaan Online Shopping: Studi Takhrij dan Syarah Hadis

Takhrij ialah upaya mengeluarkan hadis dari kitab hadis untuk mengetahui status kualitas sanad yang mencakup shahih, hasan, dha'if (Wahyuddin Darmalaksana, 2021a). Penggambaran sikap yang seharusnya dilakukan oleh umat Muslim saat menyikapi harta tergambar di dalam hadis (Hasan Nuddien et al., 2018). Salah satu hadis yang berkaitan dengan pencegahan perilaku boros ialah hadis riwayat Anas bin Malik No.11945 bab Musnad Anas bin Malik kitab Musnad Ahmad (Saltanera, 2015). Setelah status hadis tersebut diketahui kemudian akan dilakukan syarah hadis untuk mengetahui serta menjelasakan makna matan hadits (Melita, 2016). Maka dari itu penelitian ini akan membahas hadis pencegahan perilaku boros dengan cara mentakhrij dan kemudian mensyarah dengan menggunakan ilmu yang relevan dan sejalan dengannya.

Berdasarkan paparan di atas, penulis berusaha merangkai formula penelitian yaitu rumusan masalah, pertanyaan utama penelitian, dan tujuan penelitian (Wahyudin Darmalaksana, 2020a). Rumusan penelitian ini adalah terdapat hadis Nabi Saw tentang pencegahan perilaku boros terkait self healing dalam penggunaan Online Shop. Pertanyaan utama penelitian ini adalah bagaimana syarah hadis pencegahan perilaku boros terkait self healing dalam penggunaan Online shop. Tujuan penelitian ini yaitu membahas syarah hadis pencegahan perilaku boros terkait self healing dalam penggunaan Online Shop. Penelitian ini diharapkan bermanfaat bagi masyarakat yang ingin tahu bagaimana cara masyarakat millennial agar tidak menjadikan istilah self healing sebagai alasan untuk bersikap baelebih-lebihan dalam berbelanja.

\section{Metode Penelitian}

Penelitian ini merupakan pendekatan kualitatif melalui studi pustaka dalam arti tidak terjun langsung kelapangan (Wahyudin Darmalaksana, 2020b). Dengan menerapkan metode takhrij dan syarah terhadap hadis yang berkenaan dnegan pencegahan perilaku boros melalui analisis kontemporer (Wahyudin Darmalaksana, 2020a).

\section{Hasil dan Pembahasan}

Hasil dan pembahasan di bawah ini.

\section{Teks Hadis}

Berdasarkan penulusuran dengan kalimat "mengeluarkan harta" ditemukan hadis riwayat Anas bin Malik No. 11945 versi al-Alamiyah bab Musnad Anas bin Malik kitab Musnad Ahmad (Saltanera, 2015). Adapun redaksi hadis di bawah ini: 
Jurnal Riset Agama, Volume 1, Nomor 2 (Agustus 2021): 428-438

Yabqiah Rahmi/Pencegahan Perilaku Boros sebagai Self Healing dalam

Penggunaan Online Shopping: Studi Takhrij dan Syarah Hadis

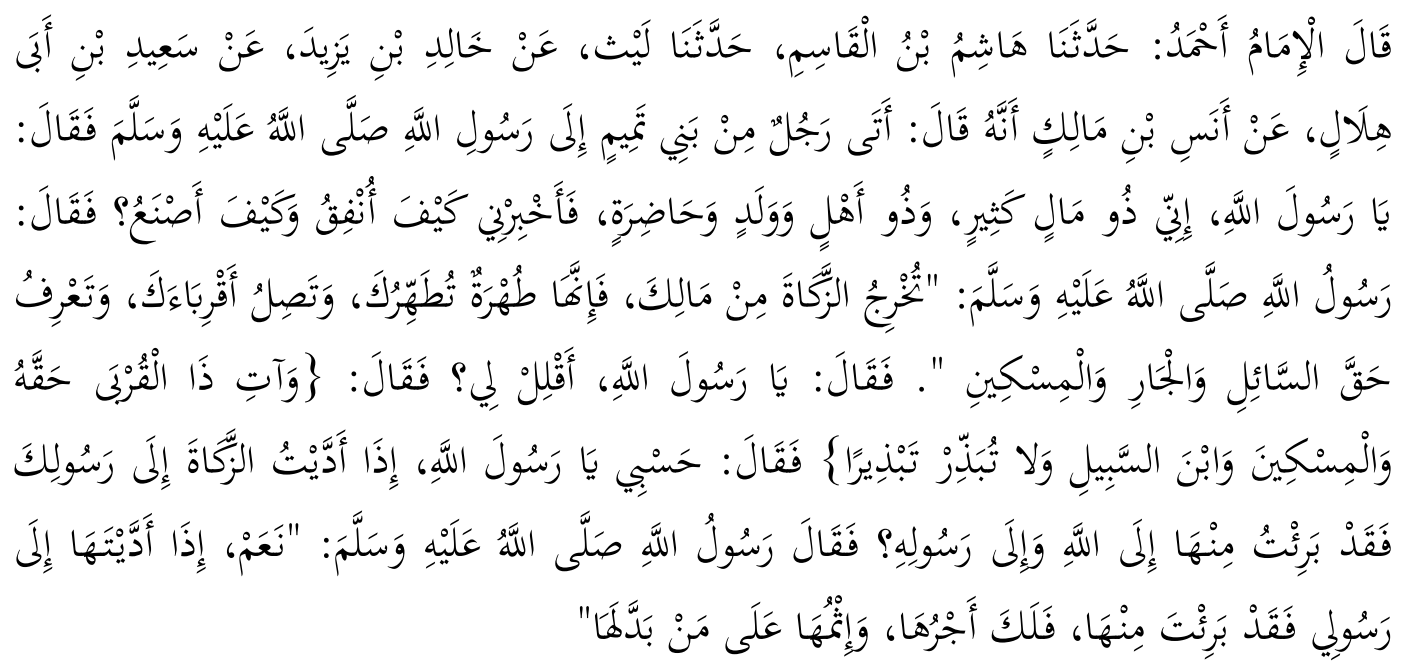

Artinya: Imam Ahmad mengatakan, telah menceritakan kepada kami [Hasyim ibnul Qasim], telah menceritakan kepada kami [al-Lais], dari [Khalid ibnu Yazid], dari [Sa'id ibnu Abu Hilal], dari [Anas ibnu Malik r.a.] yang menceritakan bahwa seorang lelaki dari Bani Tamim datang kepada Rasulullah Saw., lalu bertanya, "Wahai Rasulullah, sesungguhnya saya adalah orang yang berharta banyak, beristri dan beranak serta mempunyai pelayan, maka berilah saya petunjuk bagaimana cara yang seharusnya dalam memberi nafkah." Maka Rasulullah Saw. bersabda: Kamu keluarkan zakat harta bendamu bila telah wajib zakat, karena sesungguhnya zakat menyucikan hartamu dan dirimu; lalu berilah, kaum kerabatmu, dan jangan lupa akan hak orang yang meminta, tetangga, dan orang miskin. Lelaki itu bertanya, "Wahai Rasulullah, persingkatlah ungkapanmu kepadaku.'" Rasulullah Saw. membacakan firman-Nya: Dan berikanlah kepada keluarga-keluarga yang dekat akan haknya kepada orang miskin dan orang yang dalam perjalanan; dan janganlah kamu menghamburhamburkan (hartamu) secara boros (al-Isra: 26) Maka lelaki itu berkata, "Wahai Rasulullah, apakah dianggap cukup bagiku bila aku menunaikan zakat kepada pesuruh ('amil)mu, dan aku terbebas dari zakat di hadapan Allah dan Rasul-Nya sesudah itu?" Rasulullah Saw. menjawab: Ya. Apabila kamu menunaikan zakatmu kepada pesuruhku, maka sesungguhnya kamu telah terbebas dari kewajiban zakat dan kamu mendapatkan pahalanya. Dan sesungguhnya yang berdosa itu adalah orang yang menyelewengkan harta zakat.

\section{Daftar Rawi dan Sanad Pencegahan Perilaku Boros}

Daftar rawi dan sanad hadis terkait pencegahan perilaku pemborosan digambarkan pada Tabel 1 di bawah ini: 
Jurnal Riset Agama, Volume 1, Nomor 2 (Agustus 2021): 428-438

Yabqiah Rahmi/Pencegahan Perilaku Boros sebagai Self Healing dalam

Penggunaan Online Shopping: Studi Takhrij dan Syarah Hadis

Tabel 1. Daftar Rawi Sanad

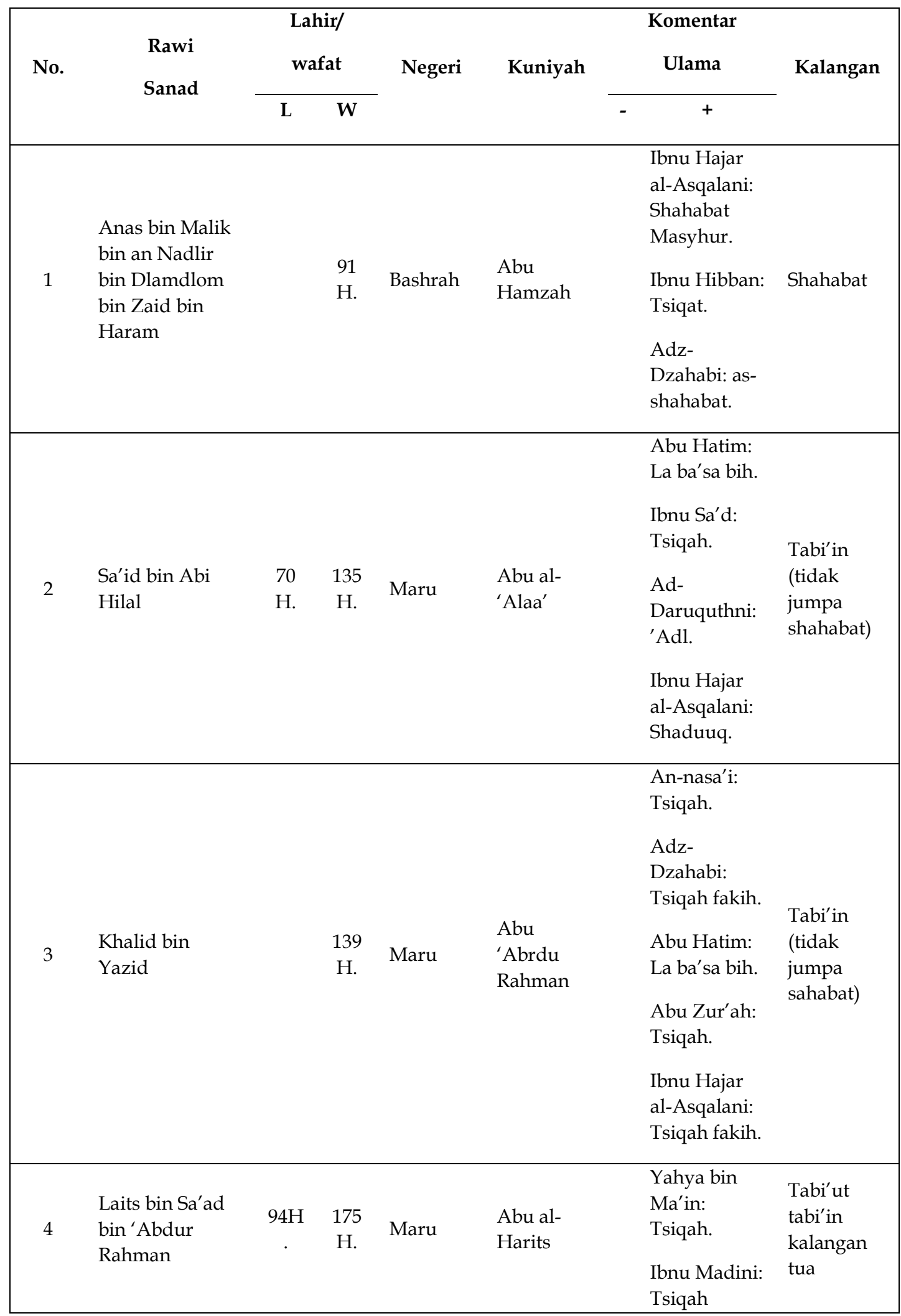


Jurnal Riset Agama, Volume 1, Nomor 2 (Agustus 2021): 428-438

Yabqiah Rahmi/Pencegahan Perilaku Boros sebagai Self Healing dalam

Penggunaan Online Shopping: Studi Takhrij dan Syarah Hadis

\begin{tabular}{|c|c|c|c|c|c|c|c|}
\hline & & & & & & $\begin{array}{l}\text { tsabat. } \\
\text { Abu Zur'ah: } \\
\text { tsiqat. } \\
\text { Ahmad bin } \\
\text { Hambal: } \\
\text { Tsiqah. }\end{array}$ & \\
\hline 5 & $\begin{array}{l}\text { Hasyim bin al- } \\
\text { Qasim bin } \\
\text { Muslim bin } \\
\text { Miqsam }\end{array}$ & $\begin{array}{c}134 \\
\mathrm{H} .\end{array}$ & $\begin{array}{c}207 \\
\mathrm{H} .\end{array}$ & Baghdad & $\begin{array}{l}\text { Abu an- } \\
\text { Nadlor }\end{array}$ & $\begin{array}{l}\text { Ibnu Abdil } \\
\text { Barr: } \\
\text { Shaduuq. } \\
\text { An-Nasa'i: } \\
\text { La ba'sa bih. } \\
\text { Adz- } \\
\text { Dzahabi: } \\
\text { Tsiqah } \\
\text { tsabat. } \\
\text { Hakim: } \\
\text { Hafidz } \\
\text { tsabat }\end{array}$ & $\begin{array}{l}\text { Tabi'ut } \\
\text { tabi'in } \\
\text { kalangan } \\
\text { tua }\end{array}$ \\
\hline 6 & $\begin{array}{l}\text { Ahmad bin } \\
\text { Muhammad bin } \\
\text { Hanbal bin Hilal } \\
\text { Asad bin Idris } \\
\text { bin Abdillah bin } \\
\text { Hayyan adz- } \\
\text { Dzuhli asy- } \\
\text { Syaibani }\end{array}$ & $\begin{array}{l}164 \\
\mathrm{H} .\end{array}$ & $\begin{array}{c}241 \\
\mathrm{H} .\end{array}$ & Baghdad & $\begin{array}{l}\text { Abu } \\
\text { Abdillah }\end{array}$ & Imam Hadis & $\begin{array}{l}\text { Mudawwi } \\
\mathrm{n}\end{array}$ \\
\hline
\end{tabular}

Tabel di atas adalah daftar rawi dan sanad hadis riwayat Ana bin Malik No. 11945 Bab Musand Anas bin Malik. Pada tabel tersebut didapati matrik rawi sanad, tahun lahir dan wafat, negeri, kunyah (panggilan) komentar ulama, dan kalangan. Pada tabel di atas terdapat dua orang rawi yang tidak diketahui tahun lahirnya, yaitu Anas bin Malik dan Khalid bin Yazid. Hadis ini diriwayatkan oleh 6 (enam) orang periwayat (rawi), dimulai dari awal sanad (rawi pertama) yaitu Anas bin Malik (kalangan shahabat) sampai rawi terakhir sekaligus menjadi pengumpul hadis (mudawwin) yakni Imam Ahmad. Rawi terakhir adalah sanad pertama sedangkan rawi pertama merupakan sanad terakhir (Wahyuddin Darmalaksana, 2021a). Sedangkan untuk pemberian komentar semua ulama memberikan komentar yang positif ( $\left.t a^{\prime} d i l\right)$.

\section{Kualitas Hadis}

Kualitas sanad bisa dikatakan shahih apabila rawi bersifat adil, dhabit, sanad bersambung, matan hadis tidak cacat dan tidak janggal (Wahyudin Darmalaksana, 2018). Terdapat ragam komentar ulama hadis 
Jurnal Riset Agama, Volume 1, Nomor 2 (Agustus 2021): 428-438

Yabqiah Rahmi/Pencegahan Perilaku Boros sebagai Self Healing dalam

Penggunaan Online Shopping: Studi Takhrij dan Syarah Hadis

terhadap perawi di antaranya ada yang berkomentar dengan penilaian negatif (al-jarh) dan penilaian positif ( $\left.t a^{\prime} d i l\right)$ (Wahyuddin Darmalaksana, 2021b). Pada tabel 1 tampak banyak ulama hadis yang berkomentar positif

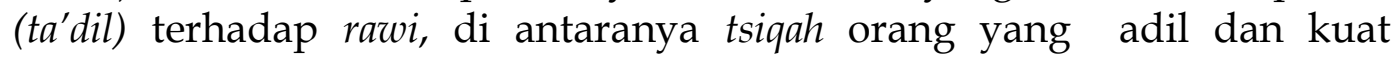
hapalan (Mukarom, 2017), shahabat masyhur, shahabat, tsiqah tsabat (orang yang teguh lagi siqat), 'adl, la ba'sa bih (orang yang tidak cacat), hafidz tsabat (kuat hapalan lagi teguh hati), shuduuq. Dengan demikian, dapat disimpulkan bahwa rawi dalam jalur sanad ini kuat hapalan dan bersifat adil. Sedangkan syarat ittishalul sanad ialah bertemu (liqa) antara penyampai hadis (guru) dan penerima hadis atau murid (Wahyudin Darmalaksana, 2018). Apabila beberapa periwayat tidak diketahui tahun lahir dan wafatnya, maka para perawi dapat dianggap berusia berkisar 90 tahun (Wahyudin Darmalaksana, 2018). Pada tabel 1 terdapat dua orang rawi yang tidak diketahui tahun lahirnya. Maka para rawi tersebut diperkirakan bertemu antara guru dan murid. Dengan kata lain, sanad hadis pada tabel 1 dapat dikatakan bersambung. Serta dilihat berdasarkan tempat penyandarannya hadis riwayat Anas bin Malik No.11945 disandarkan kepada yang memiliki kedudukan tertnggi, yaitu Rasulullah Saw. Dalam ilmu hadis disebut hadis Marfu'.

Syarat selanjutnya yang harus dipenuhi dalam menentukan kualitas sanad ialah matan hadis. Matan hadis tidak boleh janggal dan tidak boleh cacat. Dari sisi matan, teks hadis tentang pencegahan perilaku boros ini tidak janggal, tidak cacat serta matan hadis ini tidak bertentangan dengan keterangan ayat Al-Qur'an ataupun hadis mutawatir. Maka dari itu, dapat diambil kesimpulan bahwa hadis riwayat Anas bin Malik No.11945 dapat diterima sebgai hadis yang berkualitas shahih.

\section{Syarah Hadis}

Hadis dapat diamalkan (ma'mul) apabila hadis tersebut dapat diterima (maqbul) melalui proses takhrij (Wahyudin Darmalaksana, 2018). Berdasarkan proses takhrij dihasilkan bahwa status hadis riwayat Anas bin Malik No. 11945 ini berkualitas shahih mencakup sanad yang bersambung, para perawi bersifat adil dan dhabit serta di matan hadis tidak terdapat kejanggalan ataupun cacat.

Seorang manusia penting untuk mengetahui hal-hal yang berkaitan dengan budi pekerti (akhlaq) sebab untuk menjalani sebuah kehidupan dibutuhkan seperangkat tata cara dan etika (Nofiaturrahmah, 2017). Hadis riwayat Anas bin Malik No.11945 memberi petunjuk untuk tidak boros atau berlebih-lebihan serta memberi keterangan agar membelanjakan harta untuk digunakan dalam kebaikan, di antaranya: pertama, zakat adalah salah satu dari lima rukun Islam yang wajib dilaksanakan (Habib, 2016). Jika seseorang memiliki harta yang berlebih maka ia dianjurkan untuk berzakat sebab zakat memiliki banyak manfaat selain dapat 
Jurnal Riset Agama, Volume 1, Nomor 2 (Agustus 2021): 428-438

Yabqiah Rahmi/Pencegahan Perilaku Boros sebagai Self Healing dalam

Penggunaan Online Shopping: Studi Takhrij dan Syarah Hadis

mensucikan dosa pada konteks ekonomi dan sosial zakat dimaksudkan untuk mencapai keadilan sosial (Habib, 2016). Kedua, infaq dan sedekah salah satu penenanaman karakter agar terindar dari sifat atau perilaku boros ialah dengan menenamkan sifat peka dan peduli terhadap lingkungan sosial melalui kegiatan dan sedekah. Self healing dapat dilakukan dengan hal-hal sederhana seperti meluangkan waktu untuk hal yang disukai, quality time bersama keluarga atau sahabat, atau mengistirahatkan diri dengan bersantai di rumah. Apresiasi terhadap diri sendiri dengan cara berbelanja diperbolehkan namun, harus disesuaikan dengan anggaran dan batasan. Dengan adanya batasan maka dapat terhindar dari sifat atau perilaku boros. Menurut Qatadah dalam tafsir Ibnu Katsir (2011), pemborosan adalah membelanjakan harta untuk sesuatu kemaksiatan kepada Allah dan dijalan yang tidak benar. Sifat boros merupakan hawa nafsu manusia yang tidak pernah merasa cukup (Hasan Nuddien et al., 2018). Gunakan harta dengan baik dan bijaksana sebab harta adalah cobaan (Hasan Nuddien et al., 2018). Di akhirat nanti setiap orang akan ditanya perihal kenikmatan yang telah diperolehnya: tentang umurnya, jasadnya, ilmunya, amalnya, dan hartanya; bagaimana cara mendapatkannya dan untuk apa digunakannya. Dengan berinfaq, zakat dan bersedekah harta tidak akan berkurang, jangan khawatir untuk menggunakan harta dalam kebaikan. Sebab Allah itu adil, siapa yang berbuat baik, maka kebaikan pula yang akan diterima. Siapa yang berbuat jelek, maka kejelekan pula yang akan diterima (Najieb, 2012a). Mujahid berkata seandainya seseorang menginfakkan semua harta pada jalan yang benar, maka hal itu tidak termasuk pemborosan. Sebaliknya, meskipun hanya sedikit misalnya satu mudd namun dibelanjakkan bukan pada jalan benar maka hal itu disebut dengan pemborosan (Katsir, 2011).

\section{Kesimpulan}

Berdasarkan tinjauan takhrij hadis Anas bin Malik No.11945 tentang pencegehan perilaku boros berkualitas shahih baik dari segi matan ataupun sanad. Adapun syarah hadis ini menunjukkan bahwa alternatif untuk mencegah perilaku boros ialah dengan berinfaq, shadaqah dan membayar zakat. Perintah Rasul tersebut dapat dipahami sebab dengan mengelola harta dijalan yang positif itu terdapat banyak manfaat bagi dirinya sendiri ataupun orang lain. Adapun untuk mengapresiasi terhadap diri sendiri dengan cara berbelanja itu diperbolehkan namun harus sesuai dengan anggaran dan batasan agar terhindar dari perilaku boros. Penelitian ini diharapkan memberikan manfaat bagi masyarakat khususnya di kalangan millennial agar tidak menjadikan istilah self healing sebagai alasan untuk bersikap boros. Penelitian ini memiliki keterbatasan karena baru penelitian takhrij sehingga masih dibutuhkan penelitian lebih lanjut terutama terkait dengan dunia kesehatan mental. Penelitian ini 
Jurnal Riset Agama, Volume 1, Nomor 2 (Agustus 2021): 428-438

Yabqiah Rahmi/Pencegahan Perilaku Boros sebagai Self Healing dalam

Penggunaan Online Shopping: Studi Takhrij dan Syarah Hadis

merekomendasikan kepada kalangan ahli kesehatan khususnya di bidang psikologi untuk melakukan penelitian lebih lanjut mengenai self healing.

\section{Daftar Pustaka}

Bachtiar, M. A., \& Faletehan, A. F. (2021). Self-Healing sebagai Metode Pengendalian Emosi. Journal An-Nafs: Kajian Penelitian Psikologi, 6(1), 41-54. https:// doi.org/10.33367/psi.v6i1.1327

Choiriyah, M. (2017). Hadis-hadis tentang Larangan Israf dan Makhilah (Studi Ma'ani al-Hadis). Fakultas Ushuluddin dan Dakwah IAIN Surakarta.

Darmalaksana, Wahyuddin. (2021a). Herbal Tumbuhan Senna dalam Pengobatan Infeksi Covid-19: Studi Takhrij dan Syarah Hadits. PrePrint Kelas Menulis Sunan Gunung Djati Bandung, 19, 1-11.

Darmalaksana, Wahyuddin. (2021b). Kosmetik Halal sebagai Lifestyle untuk Kesehatan: Studi Takhrij dan Syarah Hadis. Pre-Print Kelas Menulis Sunan Gunung Djati Bandung, 148-162.

Darmalaksana, Wahyudin. (2018). Paradigma Pemikiran Hadis. Jurnal Aqidah Dan Filsafat Islam, 2(1), 95-106.

Darmalaksana, Wahyudin. (2020a). Formula Penelitian Pengalaman Kelas Menulis. Jurnal Kelas Menulis UIN Sunan Gunung Djati Bandung. http://digilib.uinsgd.ac.id/32620/

Darmalaksana, Wahyudin. (2020b). Metode Penelitian Kualitatif Studi Pustaka dan Studi Lapangan. Pre-Print Digital Library UIN Sunan Gunung Djati Bandung.

Fatem, A. D. T. (2015). Upaya Kepolisian Daerah Istimewa Yogyakarta dalam Menanggulangi Praktek Penipuan melalui Online Shop. Universitas Atma Jaya.

García Reyes, Luis Enrique, R. T. (2013). Gambaran Umum tentang Sikap Berlebih-lebihan. Journal of Chemical Information and Modeling, 53(9), 1689-1699.

Habib, A. A. (2016). The Principle of ZIS Accounting Bases SFAS 109. Journal of Accounting and Business Education, 1(1), 98-110.

Hasan Nuddien, Kholil Nawawi, \& Ikhwan Hamdi. (2018). Manajemen Harta dalam Perspektif Islam (Studi Analisa Hadits Riyadus Shalihin). Al-Iqtishadiyah: Ekonomi Syariah Dan Hukum Ekonomi Syariah, 4(1), 40-60.

Japar, A. W., Immanuel, D., Saputra, I., Andreanus, S., \& Surya, V. (2020). Faktor-faktor yang Mempengaruhi Penggunaan Aplikasi Belanja Online pada Masyarakat Indonesia (Studi Empiris Pada E-Commerce Indonesia). Indonesian Business Review, 2(2), 374-399. https://doi.org/10.21632/ibr.2.2.374-399

Katsir, I. (2011). Shahih Tafsir Ibnu Katsir Jilid ke-5 (Abu Ahsan Sirojuddin Hasan Bashri (ed.); Keempat). Pustaka Ibnu Katsir.

Melita, R. (2016). Penerapan Metode Term Frequency Inverse Document 
Jurnal Riset Agama, Volume 1, Nomor 2 (Agustus 2021): 428-438

Yabqiah Rahmi/Pencegahan Perilaku Boros sebagai Self Healing dalam

Penggunaan Online Shopping: Studi Takhrij dan Syarah Hadis

Frequency (TF-IDF) dan Cosine Similarity pada Sistem Temu Kembali Informasi untuk Mengetahui Syarah Hadits Berbasis Web (Studi Kasus: Hadits Shahih Bukhari-Muslim). Analisa, 4(2), 1-13.

Misbah, M. (2021). Metode dan Pendekatan dalam Syarah Hadis (Luluk Lailatul Mabrurah (ed.)). Ahlimedia Press.

Mukarom, F. R. and N. (2017). Menelaah Ilmu Hadis 2 (Latif (ed.)). PT Tiga Serangkai Pustaka Mandiri.

Munir, M. (2015). Studi tentang Hadits-hadits Nabi dalam Ilmu Ekonomi: Analisis Tematik Perspektif Integratif. UIN Malang.

Najieb, R. (2012a). Hartamu Bukan Milikmu. Risalah, 1(50), 25-29.

Najieb, R. (2012b). Mari Belajar Hidup Sederhana. Risalah, 1(50), 18-29.

Nofiaturrahmah, F. (2017). Penanaman Karakter Dermawan Melalui Sedekah. ZISWAF, 4(2), 313-326.

Retno Mangestuti. (2014). Model Pembelian Komplusif pada Remaja. UIN Malang.

Saltanera. (2015). Ensiklopedi Hadits Kitab 9 Imam. Lembaga Ilmu Dan Dakwah Publikasi Sarana Keagamaan, Lidwa Pusaka. https:/ / store.lidwa.com/get/

Yuslem, N. (2001). Ulumul Hadis (Mohamad Ilyasa (ed.); Pertama). Mutiara Sumber Widya. 